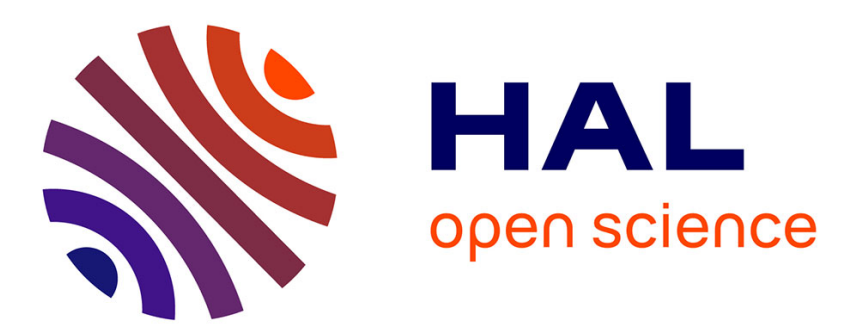

\title{
A simplified method for estimating seismic performance of small homogeneous earth dams
}

\author{
L.H Luu, G. Veylon, S. Mercklé, C. Carvajal, P.Y. Bard
}

\section{To cite this version:}

L.H Luu, G. Veylon, S. Mercklé, C. Carvajal, P.Y. Bard. A simplified method for estimating seismic performance of small homogeneous earth dams. International Symposium Qualification of Dynamic Analyses of Dams and their Equipment and of Probabilistic Assessment of Seismic Hazard in Europe, Aug 2016, Saint-Malo, France. 7 p. hal-01549920

\section{HAL Id: hal-01549920 \\ https://hal.science/hal-01549920}

Submitted on 29 Jun 2017

HAL is a multi-disciplinary open access archive for the deposit and dissemination of scientific research documents, whether they are published or not. The documents may come from teaching and research institutions in France or abroad, or from public or private research centers.
L'archive ouverte pluridisciplinaire HAL, est destinée au dépôt et à la diffusion de documents scientifiques de niveau recherche, publiés ou non, émanant des établissements d'enseignement et de recherche français ou étrangers, des laboratoires publics ou privés. 


\title{
A simplified method for estimating seismic performance of small homogeneous earth dams
}

\author{
L.-H. Luu, G. Veylon, S. Mercklé, C. Carvajal \\ Irstea, RECOVER, Aix-en-Provence, France \\ P.-Y. Bard \\ Univ. Grenoble Alpes, ISTerre, Grenoble, France
}

\begin{abstract}
We propose a new simplified method for assessing the seismic performance of homogeneous small earth dams (height $\leq 20 \mathrm{~m}$ ) founded on bedrock. Dynamic decoupled calculations were performed on seven accelerograms applied to 33 structural and geotechnical configurations. We studied the influence of embankment geometries and mechanical properties on the prediction of earthquake-induced permanent displacements estimated using Newmark analyses. This paper also discuss the relevance of this model comparing it with existing simplified models and with post-seismic field observations. A regression analysis based on easily accessible parameters characterizing the structure (yield coefficient and initial fundamental period) and the ground motion (peak ground acceleration and Arias intensity) was used to provide a pseudo-empirical predictive equation to carry out rapid preliminary seismic performance assessments.
\end{abstract}

\section{INTRODUCTION}

The Alpine region is one of the most seismically active zones in Europe. The earth dams situated in these areas are mostly mountain reservoirs. Mountain reservoirs are mainly installed in ski resorts, designed to store water used for snowmaking installations. These hydraulic structures are located in mountainous areas that are heavily populated during some periods of the year. Their failure can have disastrous consequences in terms of public safety. Therefore, the stability of mountain resevoirs under seismic loading is particularly important issue. Methods to evaluate the seismic performance of small earth dams are sorely needed in a context where geotechnical data are scarce and the determination of specific accelerograms for each site is impractical.

The seismic stability of earth dams is usually assessed using the pseudo-static approach [2]. This approach consists in analyzing the stability of a soil mass along a potential failure surface, by applying destabilizing inertia forces to the mass in the horizontal direction. Although some authors [3] have developed a methodology to determine a relevant pseudo-static seismic coefficient from seismic loading parameters and a target maximum displacement, this approach does not allow the evaluation of irreversible displacements.

Stress-deformation analyses make it possible to conduct coupled nonlinear dynamic analysis $[4,5]$. These approaches can simulate all stages of structure processing (construction, impoundment, earthquake) by taking into account the nonlinearity of constitutive laws, hydro-mechanical coupling, the effect of the history of loading, the vibration behavior of the structure, scale effects, the progressive failure of materials, etc. The main drawback of these methods stems from the practical difficulty in providing site-specific high-density and high-quality data from extensive geotechnical investigations and seismotectonic studies. These methods are generally limited to the analysis of critical projects and are not adapted to rapid or preliminary assessment of dynamic slope performance.

Permanent-displacement analysis methods aim to bridge the gap between simplistic pseudostatic approaches and complex stress-deformation analyses. Since Newmark introduced his rigid friction sliding-block method [6], a significant number of Newmark displacement-based models 
have been proposed [7, 8]. Two types of simplified methods can be distinguished: $i$ ) decoupled procedures where the dynamic response of the embankment is computed separately from the sliding mechanism and $\mathrm{ii}$ ) coupled procedures where the dynamic response is calculated simultaneously with block displacement. The decoupling hypothesis is known to be conservative, especially when the predominant frequency of the seismic excitation is close to the fundamental period of the dam [9]. In contrast, the rigid block assumption is unconservative. Some authors propose a correction formula to account for the flexibility of the sliding mass after displacements are calculated with the rigid block assumptions [10]. However, the effect of rigidity can be considered as secondary if amplification in earth dams is taken into account. Globally, decoupled rigid sliding block approaches have been successfully used in earlier studies [11, 12].

In this paper, the impact of seismic shaking parameters and site characteristics on the Newmark displacement estimates is rationalized using a decoupled rigid block analysis is emphasized. The importance of taking into account the dam's vibratory behavior. A semi-empirical formulation is proposed for estimating the Newmark displacement of homogeneous earth dams. This approach is discussed and illustrated with an example of a large mountain reservoir located in the French Alps.

\section{INPUT DATA}

\subsection{Geometry and geotechnical parameters}

Within the framework of the Italian-French RISBA project [13], the earth embankments in the cross-border Alpine area were characterized. The present work specifically focuses on the seismic performance assessment of large mountain reservoirs located between 1200 and $1800 \mathrm{~m}$. Generally constructed in flat areas, these structures are built by excavation and fill-in. A geomembrane is then installed to make them impervious. These dams are generally founded on a bedrock and the backfill material is mainly composed of moraines or shales. Their volume varies from 10,000 to several hundred thousand cubic meters.

Reflecting field studies, we model the hydraulic structures as embankments with a trapezoidal cross section, a 4-m-wide crest, 10-20 m high, and a slope from 1:2 to 1:3. The material properties used in this study are those commonly encountered in such embankments. The stability conditions were evaluated using a moist unit weight of soil equal to $20 \mathrm{kN} \mathrm{m}^{-3}$ and a range of values for the following soil properties: cohesion $c^{\prime}$, angle of internal friction $\varphi^{\prime}$, and maximum shear modulus $\mathrm{G}_{\max }$ (Table 1).

Table 1. Geometric and geotechnical properties.

\begin{tabular}{lllll}
\hline $\mathrm{H}(\mathrm{m})$ & Slope $(\mathrm{H}: \mathrm{L})$ & $c^{\prime}(\mathrm{kPa})$ & $\varphi^{\prime}\left({ }^{\circ}\right)$ & $\mathrm{G}_{\max }(\mathrm{MPa})$ \\
\hline $10,15,20$ & $1: 2,1: 2.5,1: 3$ & $0,5,10$ & $25,30,35$ & $180,300,500$ \\
\hline
\end{tabular}

\subsection{Ground motion}

This study investigates earth dams founded on the bedrock, classified as type A by [14] and exposed to earthquakes with a 5000-year return period. Table 2 presents the seven earthquakes selected to both correspond to the seismic characteristics of the French-Italian Alpine area, and match the response spectrum provided by Eurocode 8, according to the classical approach proposed by [15]. Accelerograms were selected from the European RESORCE database [1] to ensure better matching with the characteristics of Alpine seismicity for a return period equal to 5000 years. The peak ground acceleration (PGA), chosen to be the same for all accelerograms, is equal to $3.5 \mathrm{~m} \mathrm{~s}^{-2}[16]$. 
Table 2. Characteristics of real earthquake records.

\begin{tabular}{llll}
\hline $\mathrm{N}^{o}$ & Place, date, magnitude & Record & $\mathrm{I}_{\mathrm{A}}\left(\mathrm{m} \mathrm{s}^{-1}\right)$ \\
\hline 1 & Sud-Island, 2000, 6.5 & 6756-Flagbjarnarholt & 1.21 \\
2 & Sud-Island, 2000, 6.5 & 6760-Solheimar & 1.43 \\
3 & Sud-Island, 2000, 6.4 & 6791-Solheimar & 1.11 \\
4 & Sud-Island, 2000,6.4 & 6799-Kalfarholt & 2.00 \\
5 & Sud-Island, 2000, 6.4 & 6802-Thjorsartun & 0.90 \\
6 & Umbria-Marche, 1997, 5.6 & 14683-Borgo Cerreto-Torre & 1.88 \\
7 & Olfus Island, 2008, 6.1 & 16352-Selfoss-City Hall & 1.47 \\
\hline
\end{tabular}

\section{DECOUPLED ANALYSIS}

\subsection{Methodology}

This method is based on Newmark's model [6], which considers a rigid block sliding along a failure surface. The shear resistance mobilized along the sliding surface is assumed to be defined by a Mohr-Coulomb criterion. The mass starts to slide when the available strength along the failure surface is reduced so as to bring the structure to a state of limit equilibrium. Displacement occurs when the factor of safety, by definition, is equal to one, and equivalently, when the ground acceleration exceeds the yield acceleration $k_{y} \mathbf{g}$. It is worth mentioning that the yield acceleration depends only on the shear strength parameters and the geometry of the sliding mass. This parameter is independent of stiffness moduli, damping and ground motion parameters. Sliding continues until the relative velocity between the block and the base reaches zero. The cumulative block displacement is estimated by double integration over the acceleration-time history of the seismic loading. For each situation, defined by a given set of geometrical parameters and earthquake loading, this procedure systematically calculates the potential sliding of hundreds of blocks with varying geometries. Thin sliding blocks are not expected to significantly affect the geometry of the embankment and the safety level of the dams. For this reason, following the recommendations of [17], we selected the blocks whose thickness was greater than $15 \%$ of the height of the embankment. The earthquake-induced displacement finally reported, which corresponds to the most critical situation, is the largest displacement achieved among the different blocks tested.

Newmark analysis requires that the acceleration-time history of the sliding block be determined. Using QUAKE/W GeoStudio, a finite element CAD software [18], we implemented the linear equivalent method, described in [19], to compute the block acceleration at each point of the structure by applying the seismic ground acceleration at the base of the embankment. This approach is therefore considered as a decoupled approach because the acceleration-time history of the block is determined independently of the sliding-block analysis.

\subsection{Results}

We performed earthquake-induced displacement estimations for 33 different stuctures characterized by combinations obtained from the geometric and geotechnical parameters listed in Table 1. For each configuration, we implemented the seven accelerograms presented in Table 2. This section provides the analysis of these 231 calculations via our simplified method.

Figure 1 displays all the permanent displacements estimated by the present simplified decoupled procedure as a function of the ratio between critical acceleration $k_{y} \mathbf{g}$ and PGA, equal to 3.5 $\mathrm{m} \mathrm{s}^{-2}$ for all calculations. This representation, commonly used in the literature, may directly indicate the amplification phenomenon when earthquake-induced damage occurs even if $\mathrm{PGA}<k_{y}$. Our model predicts displacements in this case.

Knowing that in this study wthe PGA is kept constant for all analyses, the displacement globally decreases when $k_{y}$ increases. Distinguishing the different values of shear modulus $\mathrm{G}_{\max }$ in Figure 1 , we note that this parameter has a significant effect on the permanent displacement estimates $U$. The displacements corresponding to the lowest $\mathrm{G}_{\max }$ are roughly the highest. This trend suggests that a direct relationship between $\mathrm{U}$ and $k_{y} \mathbf{g} / \mathrm{PGA}$ is too simplistic. Including parameter $\mathrm{G}_{\max }$ to rationalize the displacement should yield a more refined prediction. We will give a more thorough discussion on this point in the following. 


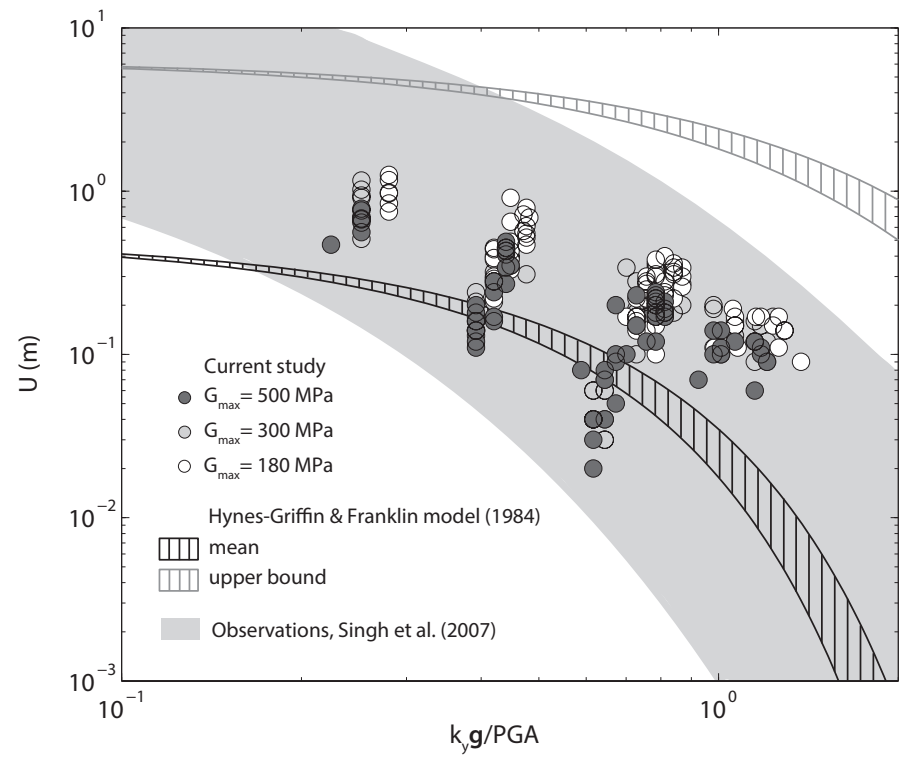

Figure 1. Displacements as a function of the critical acceleration ratio $k_{y} \mathbf{g} / \mathrm{PGA}$, where PGA=3.5 $\mathrm{m}$ $\mathrm{s}^{-2}$ and $\mathbf{g}=9.81 \mathrm{~m} \mathrm{~s}^{-2}$ : comparison with the Hynes-Griffin and Franklin model, and with actual values that were observed during seismic events as reported by Singh et al..

To assess the predictive capability of the current model, we compared the estimates with observations on embankment performance during past earthquakes. The shaded area in Figure 1 corresponds to the extent of the compiled case-history database reported by Singh et al. [20]. The results of the calculations perfectly fit within this domain. This good correlation validates the relevance of the present study.

We also compare our data to the frequently cited decoupled analysis developed by Hynes et al. [21]. Their method takes into account amplification of ground motions in the embankment by means of a shear-beam model of the embankment-foundation system. Contrary to our procedure, they make the assumption that the sliding-block analysis and the amplification analysis can be decoupled. In Figure 1, we chose to report the mean and the upper-bound prediction when including the amplificator factor at the resonance. According to their paper, this factor varies with the ratio between the embankment's and the sliding block's heights in the following range: between 2.5 and 3 for the mean displacement and between 3.5 and 4.5 for the upper bound. The prediction range displayed in our graph corresponds to this variation. Overall, the Hynes-Griffin and Franklin model can describe the data resulting from our study but does not constrain them sufficiently, yielding a relatively large standard deviation.

\section{PREDICTIVE MODEL}

\subsection{Functional form}

A practical tool for seismic risk assessment of large mountain reservoirs situated in the Alpine region is provided. The site parameters that are available are therefore analyzed without the dynamic computation being undertaken. The time, computational efforts and cost for seismic performance assessment can thus be greatly reduced.

Concretely, two characteristic earthquake parameters are considered as input data, namely the Arias intensity $\mathrm{I}_{\mathrm{A}}$ (Table 2) and PGA (set at $3.5 \mathrm{~m} \mathrm{~s}^{-2}$ ), and two characteristic structural parameters, namely the yield acceleration $k_{y}$ and the earth structure fundamental period $\mathrm{T}_{1}$. On the one hand, $k_{y}$ includes cohesion, internal friction, structure height and slope effects. On the other hand, $\mathrm{T}_{1}$ is directly related to $\mathrm{G}_{\max }$, such that:

$$
T_{1}=\frac{2 \pi}{2.4} \frac{\mathrm{H}}{\sqrt{\mathrm{G}_{\max } / \rho}}
$$



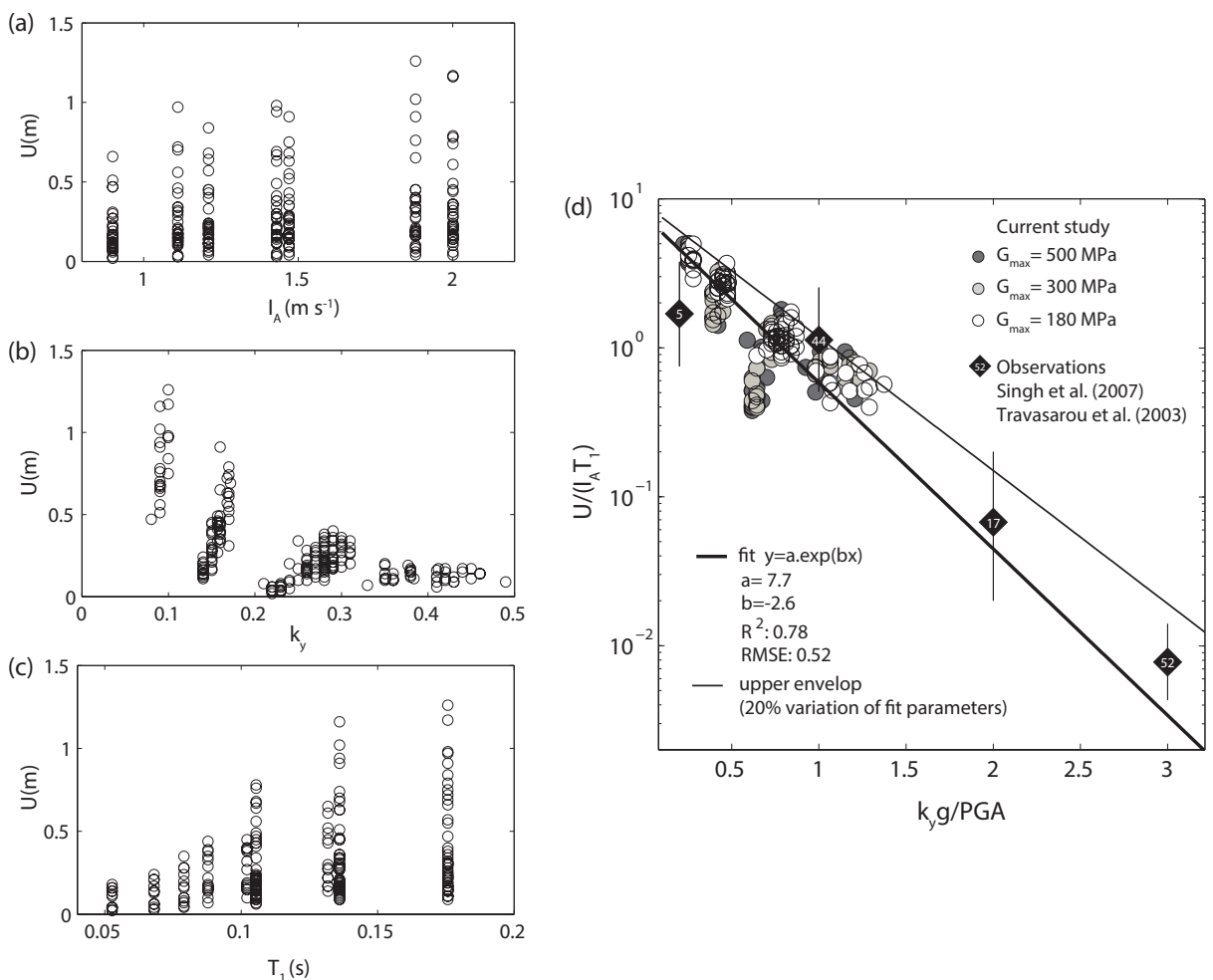

Figure 2. Displacement predicted by the present model plotted versus: (a) Arias intensity, $\mathrm{I}_{\mathrm{A}}$ (b) unitless yield acceleration $k_{y}$, (c) reservoirs fundamental period $\mathrm{T}_{1}$. (d) Dimensionless dispacement as a function of critical acceleration ratio $k_{y} \mathbf{g} / \mathrm{PGA}$, where $\mathrm{PGA}=3.5 \mathrm{~m} \mathrm{~s}^{-2}$ and $\mathbf{g}=9.81 \mathrm{~m} \mathrm{~s}^{-2}$ : regression analysis and comparison with observations.

Table 3. Case-history data with reference to [20].

\begin{tabular}{lllll}
\hline $\mathrm{N}^{o}$ & $\mathrm{~T}_{1}(\mathrm{~s})$ & Magnitude & $\Delta(\mathrm{km})$ & $\mathrm{U}_{\text {horizontal }}(\mathrm{m})$ \\
\hline 5 & 0.53 & 6.8 & 24 & 0.4 \\
17 & 0.69 & 6.0 & 29 & 0.001 \\
44 & 0.59 & 6.8 & 17 & 0.3 \\
52 & 0.94 & 7.6 & 11 & 0.013 \\
\hline
\end{tabular}

where $\mathrm{H}$ is the embankment height and $\rho$ its density.

Figure 2a-c represents permanent displacements $\mathrm{U}$ for all data as a function of $\mathrm{I}_{\mathrm{A}}, k_{y}$ and $\mathrm{T}_{1}$, respectively. Concerning all calculations (seven accelerograms and 33 geotechnical situations), these graphs reflect raw variations of $\mathrm{U}$, which roughly increases with $\mathrm{I}_{\mathrm{A}}$ and $\mathrm{T}_{1}$ (to a lesser degree for $\mathrm{I}_{\mathrm{A}}$ ), and which globally decreases with $k_{y}$.

To rationalize these different input parameters' influences, Figure $2 \mathrm{~d}$ plots the dimensionless displacement $\mathrm{U} /\left(\mathrm{I}_{\mathrm{A}} \mathrm{T}_{1}\right)$ versus the yield acceleration ratio $k_{y} \mathbf{g} / \mathrm{PGA}$. This representation gathers all the data into a single curve within a reasonably narrow band. In particular, compared to the analysis in Figure 1, we succeed here in rendering the relationship independent of $\mathrm{G}_{\max }$ by considering $\mathrm{T}_{1}$. The exponential law fits the data well $\left(R^{2}=78 \%\right)$, spanning less than one order of magnitude, which yields a satisfactory regional-scale assessment. The multi-parameter correlation above leads to the following functional form for estimating earthquake-induced displacements:

$$
\ln \mathrm{U}=\ln \mathrm{I}_{\mathrm{A}}+\ln \mathrm{T}_{1}+2-2.6 \frac{\mathrm{k}_{\mathrm{y}} \mathbf{g}}{\mathrm{PGA}}
$$

To determine how general this correlation might be, we can discuss its asymptotic behavior. On one hand, this law predicts that $\mathrm{U}$ is proportional to $\mathrm{I}_{\mathrm{A}}$ and $\mathrm{T}_{1}$ when $k_{y}$ tends to zero. In the case of a zero-friction motion, one could indeed assume, as a first approximation, that the seismic intensity and the structure's vibratory behavior predominate in the sliding block mechanism. 


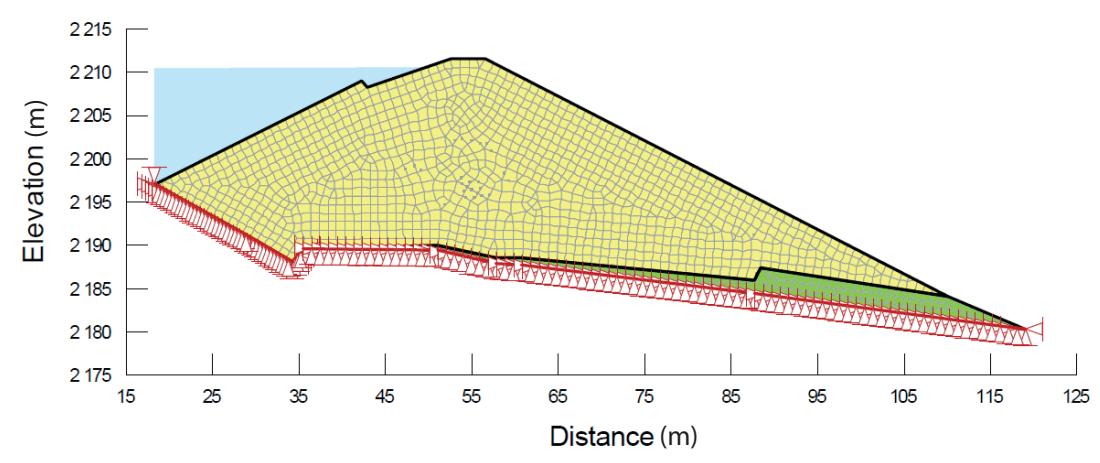

Figure 3. Meshing of a representative cross section of the Vars Dam.

Nevertheless, practical experience shows that for critical ratio $k_{y} \mathbf{g}$ /PGA below around 0.3 , our Newmark-based model would no longer be appropriate because of the need to consider liquefaction or severe loss of shear strength due to very severe earthquakes. On the other hand, this law tends to zero displacement when the seismic ground motion tends to zero, i.e for very high $k_{y} \mathbf{g} / \mathrm{PGA}$.

Lastly, we propose to further compare these results to actual post-seismic observations. The field data reported by Singh et al. indicate earth dam fundamental periods, earthquake magnitudes, epicentral distances, and observed damage in terms of permanent displacements (Table 3). To obtain the dimensionless displacements, we need the Arias intensity of these seismic events. To this end, we use the curves of Arias intensity versus epicentral distance, depending on the magnitude, presented in [22]. We thus add an estimate of $U /\left(\mathrm{I}_{\mathrm{A}} \mathrm{T}_{1}\right)$ to Figure $2 \mathrm{~d}$ for case histories (with reference to the database reported in [20]) number 5, 17, 44 and 52. Although the chartbased use of the empirical curves in [22] generate large error bars, all points match the domain predicted by our exponential law. We therefore built a semi-empirical predictive equation, calibrated for a specific case study (in particular for a fixed PGA), that is also suitable for a wide range of observational data.

\subsection{Case study}

Finally, we apply the simplified method to assess the seismic performance of the Vars Dam located in the southern Alps for which we have an accurate description from its design phase and the construction site supervision. This mountain reservoir was built in 2010 using cut-and-fill methods and retains $125,000 \mathrm{~m}^{3}$ of water. The dam is $21 \mathrm{~m}$ high with a downstream slope of 1:2. Mainly composed of moraines, the soil is characterized by a moist unit weight of soil equal to $20 \mathrm{kN} \mathrm{m}^{-3}$, a cohesion of $5 \mathrm{kPa}$, and an angle of internal friction of $35^{\circ}$. The representative shear wave velocity is measured by means of a mutichannel analysis of surface wave (MASW) seismic method. The corresponding maximum shear modulus is evaluated as $\mathrm{G}_{\max }=480 \mathrm{MPa}$. For this case study, we generate a collection of ten specific synthetic accelerograms following the same methodology as presented above, considering a return period $\mathrm{T}=2500$ years characterized by $\mathrm{PGA}=2.8 \mathrm{~m} . \mathrm{s}^{-2}$, in accordance with the current European regulations.

Figure 3 shows the numerical model implemented in the finite element method calculations. The decoupled analysis performed as presented above gives Newmark displacements $U=3.0-$ $13.0 \mathrm{~cm}$. From a pseudo-static analysis we acquire a yield acceleration of $k_{y} \mathbf{g}=3.8 \mathrm{~m} \mathrm{~s}^{-2}$. The first fundamental period of the dam is estimated as $T_{1}=0.12 \mathrm{~s}$. For the PGA considered, the range of Arias intensities is evaluated as $\mathrm{I}_{\mathrm{A}}=0.4-2.9 \mathrm{~m} \mathrm{~s}^{-1}$ [22]. We therefore calculate Newmark displacements of $U=1.0-7.5 \mathrm{~cm}$ using the simplified formula (Eq. 2). This illustrative example confirms that the predictive model is able to give a similar range of seimic performance indices than dynamic calculations.

\section{CONCLUSION}

A predictive displacement-based method for use in large mountain reservoirs located in the crossborder French-Italian Alpine area has been developed. Based on the Newmark analysis method, 
this numerical procedure consists in a decoupled dynamic analysis based on the implementation of the linear equivalent approach. The numerical results are consistent with field data and provide consistent results with regards to other existing simplified methods. Then, attempting an engineering approach, the results of simulations were used to construct a regression law predicting seismic displacements on the basis of usually available input parameters, namely in terms of the critical acceleration ratio, Arias intensity and the structure's fundamental period. Ongoing studies will focus on a refined integration of spectral parameters in the formulation of the simplified method. We then intend to improve our understanding of the failure mechanism by means of nonlinear fully coupled dynamic simulations, carrying out a graduated approach from regional to site-specific seismic risk assessment.

\section{REFERENCES}

Akkar, S., Sandikkaya, M., Senyurt, M., Azari Sisi, A., Ay, B., Traversa, Douglas, J., Cotton, F., Luzi, L., Hernandez, B., S., G., 2014. Reference database for seismic ground-motion in europe (resorce). Bulletin of Earthquake Engineering 12, 311-339.

Terzaghi, K., Paige, S., 1950. (Ed.) Mechanisms of landslides Application of Geology to Engineering practice, Geological Society of America, 83-123.

Papadimitriou, A. G., Bouckovalas, G. D., Andrianopoulos, K. I. 2014. Methodology for estimating seismic coefficient for performance-based design of earth dams and tall embankments, Soil Dynamics and Earthquake Engineering, 56, 57-73.

Clough, R. W., Chopra, A. K. 1966. Earthquake stress analysis in earth dams, ASCE Journal of the Engineering Mechanics Division, 92, 197-211.

Kramer, S. L. 1996. Geotechnical Earthquake Engineering Prentice Hall, Upper Saddle River, N.J.

Newmark, N. M. 1965. Effects of earthquakes on dams and embankments, Geotechnique, 15, 139-159.

Cai, Z., Bathurst, R. J. 1996. Deterministic sliding block methods for estimating seismic displacement of earth structures, Soil Dynamics and Earthquake Engineering, 15, 255-268.

Meehan, C. L., Vahedifard, F. 2013. Evaluation of simplified methods for predicting earthquake-induced slope displacement in earth dams and embankments, Engineering Geology, 152, 180-193.

Gazetas, G., Uddin, N. 1994. Permanent deformation on preexisting sliding surface in dams, Journal of Geotechnical Engineering Division, ASCE, 120(11), 2041-2061.

Rathje, E. M., Antonakos, G. 2011. A unified model predicting earthquake-induced sliding displacements of rigid and flexible slopes, Engineering Geology, 122, 51-60.

Seed, H. B.; Makdisi, I. F., De Alba, P. 1978. Performance of earth dams during earthquakes, Journal of Geotechnical Engineering Division, ASCE, 104(7), 967-994.

Pradel, D. P.; Smith, P. M.; Stewart, J. P., Raad, G. 2005. Case history of landslide movement during the Northridge earthquake, Journal of Geotechnical and Geoenvironmental Engineering, 131(11), 13601369.

RISBA Rischio degli sbarramenti articiciali - Risques des barrages Piedmont region, Aoste valley region, Irstea, 2014.

Eurocode8 Design of structures for earthquake resistance - Part 1: General rules, seismic actions and rules for buildings Brussels, Belgium, 2004.

Gasparini, D. A., Vanmarcke, E. H. 1976. Simulated earthquakes compatible with prescribed response spectra, Massachusetts Institute of Technology, Publication No. R76-4, Cambridge, Massachusetts.

Bard, P. Y., Causse, M. 2015. Generation of synthetic accelerograms for alpine dams, Technical report, ISTerre, Grenoble, France.

OFEG Dam safety - Base document for the verification of dams subjected to earthquakes OFEG, serie Eaux, version 1.2, 2003.

GeoSlopeInternationalLtd. Geostudio a product suite for geotechnical modeling Geo-slope International Ltd, 2004.

Seed, H. B., Idriss, I. M. 1970. Soil moduli and damping factors for dynamic response analysis, Report No. EERC 70-10 University of California, Berkeley.

Singh, R., Roy, D., Das, D. 2007. A correlation for permanent earthquake-induced deformation of earth embankments, Engineering Geology, 90, 174-185.

Hynes-Griffin, M. E., Franklin, A. G. 1984. Rationalizing the seismic coefficient method, Misc. Paper GL-84-13 U.S. Army Waterway Experiment Station, Vicksburg, Mississipi.

Travasarou, T., Bray, D., Abrahamson, A. N. 2003. Emprirical attenuation relationship for Arias Intensity, Earthquake Engineering and Structural Dynamics, 32, 1133-1155. 